This item was submitted to Loughborough's Research Repository by the author.

Items in Figshare are protected by copyright, with all rights reserved, unless otherwise indicated.

\title{
Rohacell radomes for delicate antennas on the body at $2.4 \mathrm{GHz}$
}

\author{
PLEASE CITE THE PUBLISHED VERSION \\ https://doi.org/10.1109/LAPC.2015.7366096 \\ PUBLISHER \\ (c) IEEE
}

VERSION

AM (Accepted Manuscript)

PUBLISHER STATEMENT

This work is made available according to the conditions of the Creative Commons Attribution-NonCommercialNoDerivatives 4.0 International (CC BY-NC-ND 4.0) licence. Full details of this licence are available at: https://creativecommons.org/licenses/by-nc-nd/4.0/

\section{LICENCE}

CC BY-NC-ND 4.0

\section{REPOSITORY RECORD}

Ojerinde, Oluwaseun A., Dina A.H. Al-Saffar, R.M. Edwards, and C.J. Panagamuwa. 2019. "Rohacell Radomes for Delicate Antennas on the Body at 2.4ghz". figshare. https://hdl.handle.net/2134/26554. 


\title{
Rohacell Radomes for Delicate Antennas on the Body at $2.4 \mathrm{GHz}$
}

\author{
O. A. Ojerinde \\ School of Electronic, Electrical and Systems Engineering, \\ Loughborough, Leicestershire, \\ England, UK \\ O.A.Ojerinde@lboro.ac.uk \\ D. Al-Saffar \\ School of Electronic, Electrical and Systems Engineering, \\ Loughborough, Leicestershire, \\ England, UK \\ D.Al-Saffar@lboro.ac.uk
}

\author{
R. M. Edwards \\ School of Electronic, Electrical and Systems Engineering, \\ Loughborough, Leicestershire, \\ England, UK \\ R.M.Edwards@lboro.ac.uk \\ C.J. Panagamuwa \\ School of Electronic, Electrical and Systems Engineering, \\ Loughborough, Leicestershire, \\ England, UK \\ C.J.Panagamuwa@lboro.ac.uk
}

\begin{abstract}
This paper presents the use of two generic on-body antenna types, a probe and a magnetic dipole with and without a radome constructed of Rohacell. Its is shown that Rohacell minimally attenuates the electromagnetic signal transmitted or received by the antenna concluding to the cover being essentially transparent to radio waves at $2.4 \mathrm{GHz}$ and $5.8 \mathrm{GHz}$. In on-body meaurements radomes can be used to protect the antenna surfaces from damage and protect nearby personnel from being accidentally struck by quickly rotating antennas. Performance of two on-body antennas is considered on and off the body by measurement and simulation. Results show that the Rohacell protection has negligible effect on the performance of the antenna systems regardless of loading by humans and polarity. This paper aims to enlighten use of Rohacell to protect antennas used for body centric experiments and experiments in bodycentric settings.
\end{abstract}

Keywords- Rohacell; on-body communication; circular ground plane monopole antenna; Loop antenna, antenna safety.

\section{INTRODUCTION}

Advances in technology have made it possible to have wearable hardware for communication and sensing incorporated into personal area networks (PANs) and body area network (BANs). Body centric communication systems play a very important role in the fourth generation communication system (4G) [1] . To support antenna and propagation research on wireless personal area networks, the IEEE 802.15 standardization group was established [2]. Applications have been applied to athletes, paramedics, fire-fighters and military personnel. This can be seen as a trend triggered by innovation in mobile phones [1].

Extensive research has been done in body centric communications [1]-[11]. It was concluded in [1] that the monopole is the best antenna family for on-body propagation in comparison to top loaded monopoles and PIFAs. Also in [1] it was suggested that antennas that direct their radiation along the body surface with appropriate polarisation are needed for on-body links. This concludes to the need for a second linear polarisation for inter-body communication. Note that because of the properties of tissue the choice of polarisation is also frequency dependent. Specifying the radiation pattern requirement for a system is difficult. At $2.4 \mathrm{GHz}$ for maximum path gain, links between antennas on-body should have a monopolar like pattern with polarisation oriented normal to the body surface.

In carrying out on-body measurements, various approaches have been followed. Some researchers opt for simulation packages combined with mathematically modelled phantoms [12]-[14] while some have used real phantoms filled with tissue simulating liquid to represent various parts of the body [15]-[18]. Several experiments have also been seen using volunteers for the on-body measurements [4], [11], [19], [20]. In [21]-[23], antennas were worn on volunteers for experiments on fading interactions with various environments. In [24], a simulator was used for the on-body measurement with various movements. This gives the opportunity to perform the experiment while changing different variables to suit the environment expected for the experiment. In [25], a phantom was used to check the performance of antennas in a multipath environment. The experiment was done in a reverberation chamber for repeatability. The employment of a phantom reduces variation in results attributed to movement of the body. In [17], a study was done to determine the effects of antenna proximity to the body. This was done using rectangular and cylindrical phantoms to represent the human torso and compared with results obtained using volunteers. The experiment showed that a cylindrical phantom can be used to represent the human torso in a situation where repeatability in experiment is important.

Embedding of technology on and in the body is a growing trend in the field of mobile communications [26]. The human body introduces undesirable effect to the antenna in the near field. This is important in terms of safety and electronic performance.

On-body radio propagation has helped improve telemedicine. Patients can be monitored without coming in contact with a doctor. Telemedicine system can be categorised in two systems, the system on the body surface and the one internal with implants in the body [5]. In [27], work was done 
on an infant telemeter. It was concluded a loop antenna in best for communication in an on-body system. The different body centric applications combined with global positioning system (GPS), navigation system, cellular, Bluetooth and UWB has made it possible to achieve the low power signal budget using body centric antennas [28].

With the use of these technologies on the body, an improved testing of the antenna on the body is necessary. In this paper, a comparison between test results for antennas with and without protective Rohacell radome is presented. This paper discusses circular ground plane monopoles and loop antennas protected with Rohacell radomes that increase safety and mechanical stability.

\section{EXPERIMENTAL DESCRIPTION}

\section{A. Antenna Simulation and Construction}

First a set of probe antennas was built in the Loughborough University Electronics workshop using the parts simulated in Empire XCcel. A U.FL-SMT PCB receptacle connector was used in antenna. The choice of this connector was based on its size. The antenna constructed for the on-body measurement consisted of a quarter-wavelength monopole antenna on an isolated circular ground plane. The monopole perpendicular to the surface of the body is known to produce surface waves that couple well with human tissue [29]. The antenna was built to resonate at $2.4 \mathrm{GHz}$. For a quarter wavelength monopole antenna, the antenna length is ideally $31.25 \mathrm{~mm}$. The ground plane of the antenna was made circular. This helps avoid corner effects introduced by more typical rectangular shaped ground planes and makes the antenna independent in azimuthal alignment with the body part to which it will be attached. After some initial simulations the ground plane was set at $100 \mathrm{~mm}$ diameter. This was set to meet the requirement of the ground plane being a minimum of a quarter-wavelength [30] and also for convenience when mounting it on the body. The ground plane was built from a one sided copper FR4 substrate. Fig. 1 and Fig. 2 show the dimensions of the antenna.

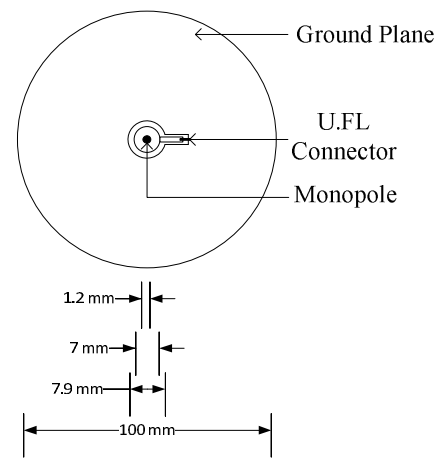

Fig.1. Top view of the monopole antenna.

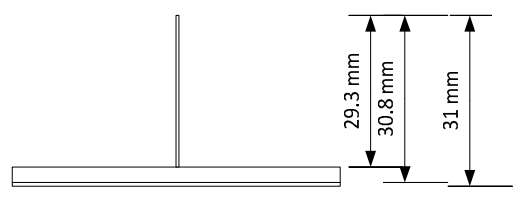

Fig.2. Side view of the monopole antenna

The antenna was simulated using the Empire XCcel EM simulation package [31]. In the simulation package, the antenna was initially built with the FR4 substrate and a monopole mounted in the centre with the feed from below the ground plane.

\section{B. Introduction of Rohacell to Monopole Antenna}

The antenna was later modified with ROHACELL $₫ 31 \mathrm{HF}$ to cover the monopole and the source of the feed. The source of the feed was isolated using a $5 \mathrm{~mm}$ thick Rohacell cut in the shape of the circular ground plane. This material is referred to as solid air since ideally when clean it has little effect on the antenna characteristics. The properties of ROHACELL ${ }^{\circledR} 31$ $\mathrm{HF}$ are given in the Table 1.

TABLE 1 ROHACELL PROPERTIES

\begin{tabular}{|c|c|c|}
\hline Dielectric & Permittivity $\varepsilon_{\mathrm{r}}$ & Loss tangent $\delta$ \\
\hline ROHACELL® $31 \mathrm{HF}$ & 1.05 & $<0.0002 @ 2.5 \mathrm{GHz}$ \\
\hline
\end{tabular}

After simulation with the ROHACELL $\AA 31 \mathrm{HF}$, the antenna is simulated on the body. The antenna is tuned to work at $2.4 \mathrm{GHz}$ when attached to the body. For the simulation on the body, the Brooks man was used to represent the human. The Brooks man has the whole body details of a human with all the organs well detailed for simulation purposes. Adjustments were made to the height of the monopole to get resonance at $2.4 \mathrm{GHz}$ on the body. The Rohacell provided protection and rigidity for the antennas that was important during measurement.
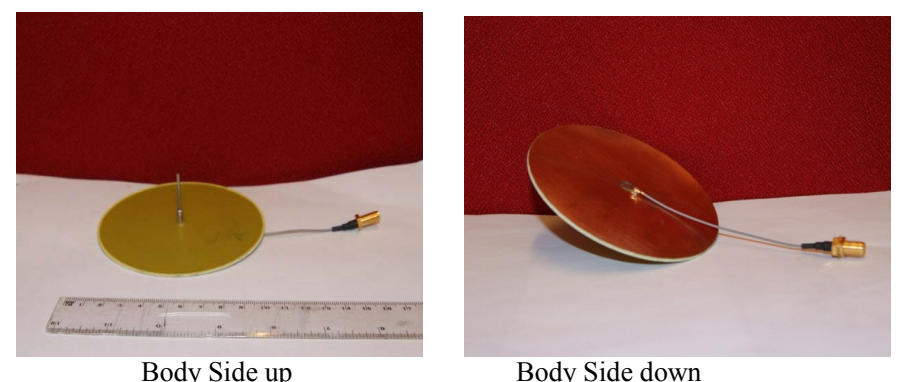

Fig.3. Monopole antenna without Rohacell. 


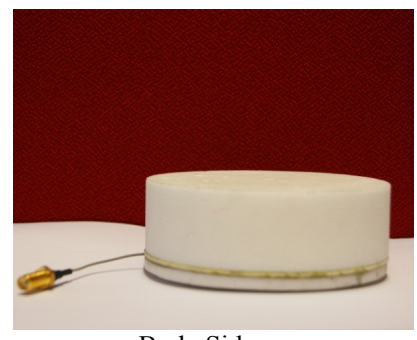

Body Side up

Fig.4. Monopole antenna with Rohacell.

The built antenna was then measured in the communication division's small anechoic chamber. In the simulations carried out, it was established that the Rohacell had no significant effect on the antenna. For the purpose of this test in the anechoic chamber, the Rohacell used to protect the connector on the ground plane is removed. The antenna efficiency and gain was checked. The $\left|\mathrm{S}_{11}\right|$ and radiation pattern were measured in free space. In Figures 5 and 6 the antenna is shown mounted above the positioner.

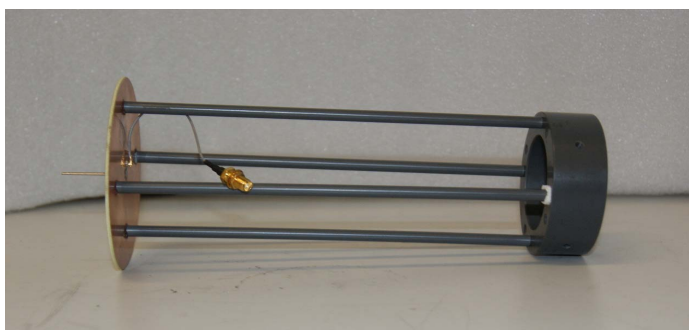

Fig.5. Monopole antenna mounted on the support pole.
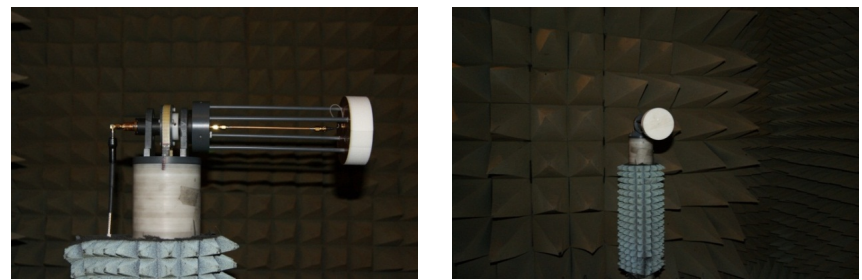

Fig.6. Monopole antenna mounted on the support pole in the anechoic chamber.

\section{RESULT}

The s-parameters of the simulated antenna with and without the ROHACELL $\AA 31 \mathrm{HF}$ was compared to check the effect of the ROHACELL ${ }^{\circledR} 31 \mathrm{HF}$ on the antenna in free space. The results are presented in the graph shown in Fig. 7.

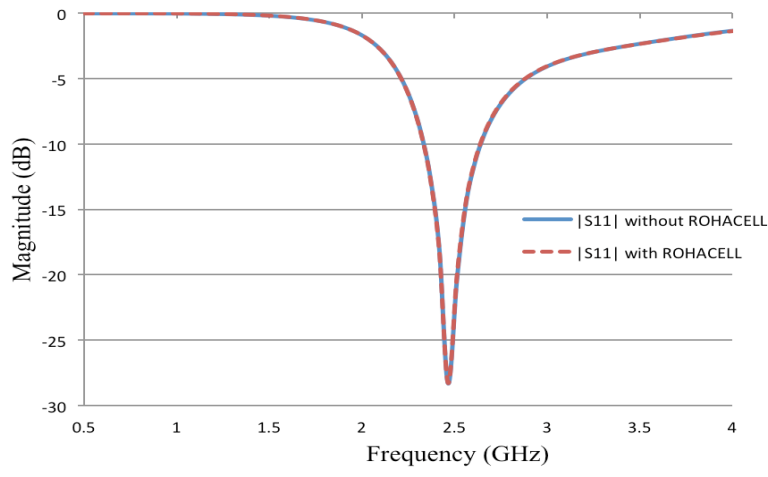

Fig.7. Simulated $\left|\mathrm{S}_{11}\right|$ of a $\lambda / 4$ antenna simulated with and without the Rohacell radome.
The $-3 \mathrm{~dB}$ bandwidth for the antenna is $43 \%$. The results showed the antennas behaved alike with and without the Rohacell. This showed the Rohacell was useful to provide more rigidity for the antenna but did not change the results in any significant way.

From the measurement taken in the chamber, the $\left|S_{11}\right|$ for the antenna at $2.4 \mathrm{GHz}$ was about $-18 \mathrm{~dB}$. The efficiency of an antenna deals with the radiated power compared to power delivered to the antenna. In the chamber, the radiation efficiency and total efficiency of the antenna was checked. The radiation efficiency is the ratio of radiated power to the input power of the antenna while total efficiency account for the loss in the input terminal and within the antenna structure. The total efficiency of an antenna is less than the radiated efficiency of the same antenna. The graph in Fig. 8 indicated the radiated and total efficiency of the monopole antenna within a frequency range.

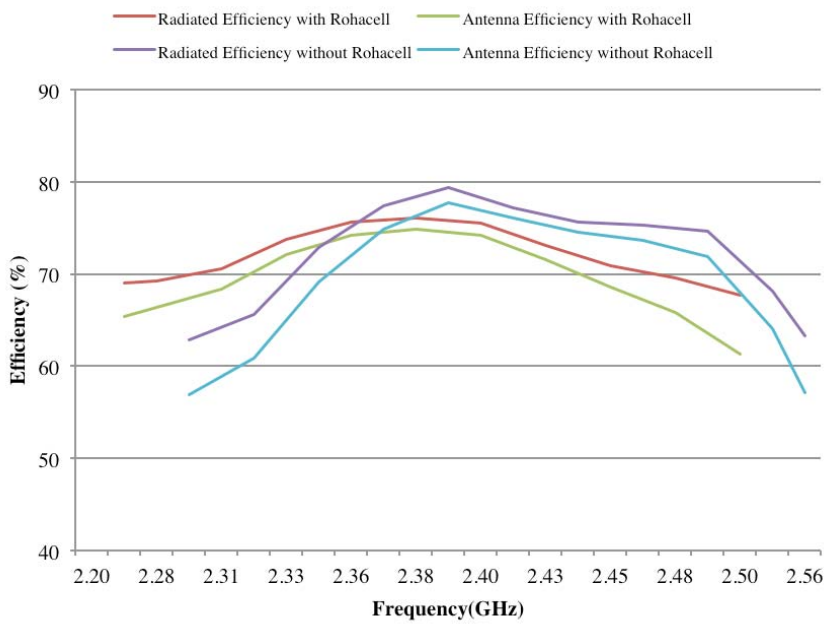

Fig.8. Results of the radiated and total efficiency for a $\lambda \& 4$ monopole with and without radome.

The $\left|\mathrm{S}_{11}\right|$ of the antenna is measured with and without the Rohacell (RH) protective layer. The built antenna has a higher $\left|\mathrm{S}_{11}\right|$ than the simulated one. This can be due to material and connectors used to build the antenna. Fig. 9 shows the $\left|S_{11}\right|$ for the simulated and built antenna with and without the $\mathrm{RH}$ protector.

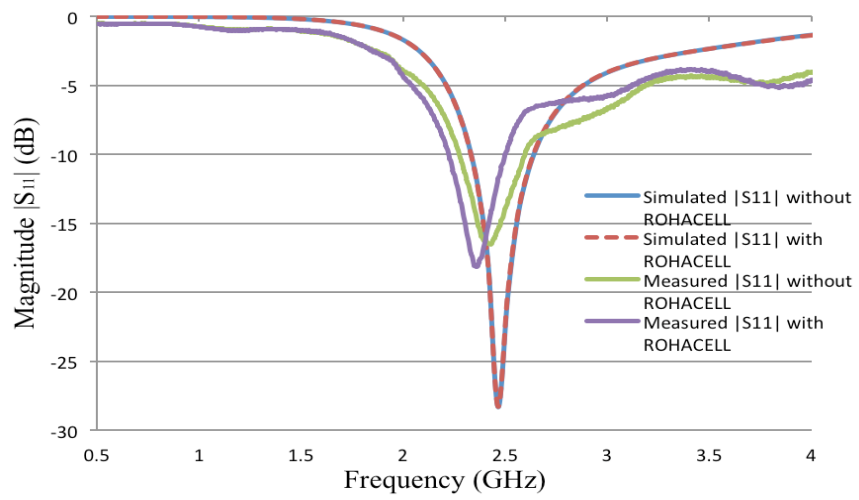

Fig.9. $\left|\mathrm{S}_{11}\right|$ from simulation and built antenna with and without Rohacell 
The results for the measured monopole were similar but not the same as the simulations. It was seen that the antenna was more inductive than expected (longer) and therefore resonated at the lower frequency. Also it was seen that the $\mathrm{Q}$ of the antenna was poorer by approximately $10 \mathrm{~dB}$. These differences were thought to be caused mainly by cabling and soldered joints on the monopole that were not simulated. However a resonant point of $-17 \mathrm{~dB}$ and resonance close to $2.4 \mathrm{GHz}$ was reasonable and therefore the antenna was not tuned again. Efficiency for this experiment was not critical but measured results of $75 \%$ or more did validate that the antenna was radiating. The built antenna had a shift in frequency response to a lower frequency but with the $10 \mathrm{~dB}$ bandwidth range, it still worked properly at $2.4 \mathrm{GHz}$. An increase of around $10 \mathrm{~dB}$ is noticed in the simulated and built antenna. The radiation pattern of the antenna with and without the Rohacell protection was obtained in the anechoic chamber. This result is shown in the Fig. 10.
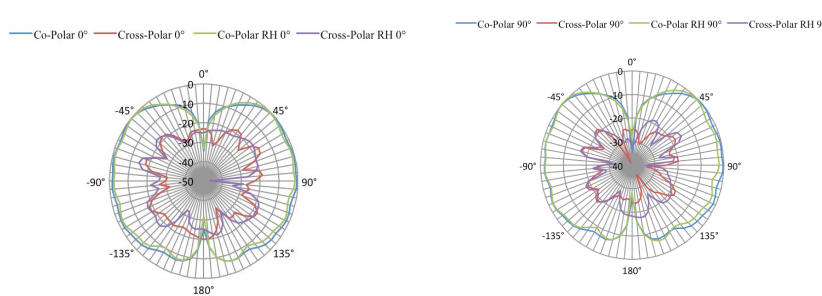

Fig.10. Measured radiation patterns of the monopole antenna with and without Rohacell (RH).

The radiation pattern in the Fig. 10 is for the co-polar and cross-polar plane at $0^{\circ}$ and $90^{\circ}$ for measurement in the anechoic chamber. The results show the Rohacell has minimal effect on the antenna's normal working state.

In order to further investigate the use of the Rohacell as a radome a second antenna, a loop antenna, operating at $5.8 \mathrm{GHz}$ was sythesised. CST was used for the model. The simulated results are shown in Fig. 11. The main beam from this antenna is now horizontally polarized with reference to the plane in which the surface of the bodies skin exists. The previous antenna was vertically polarized. In this case a four layer phantom was used consisting of skin, fat, muscle and bone. The results suggested the Rohacell radome was also transparent to radio waves at $5.8 \mathrm{GHz}$.

\section{CONCLUSION}

The work presented in this paper has discussed the use of Rohacell as a radome for on-body antennas. Two frequencies, $2.4 \mathrm{GHz}$ and $5.8 \mathrm{GHz}$ were considered. The results from the simulation showed the antenna resonated at the expected frequencies with or without the Rohacell protective layer. Also results from the experiments showed the antenna behaved alike with and without the Rohacell. This shows the Rohacell was useful to provide more rigidity for the antenna but did not change the results in any significant way. It should be noted that the Rohacell was clean and kept packed in polythene prior to being used since it was likely that carbon dust from absorbers and moisture might change the results.

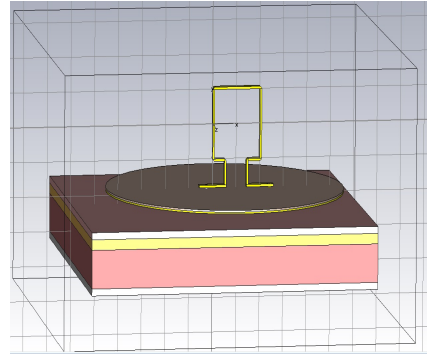

(a)

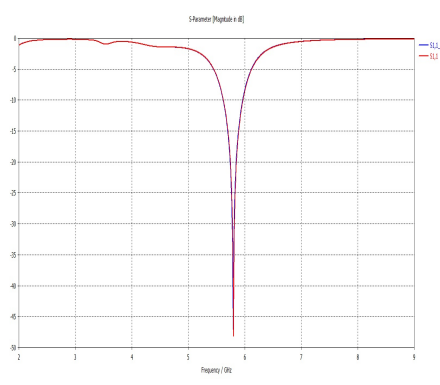

(c)

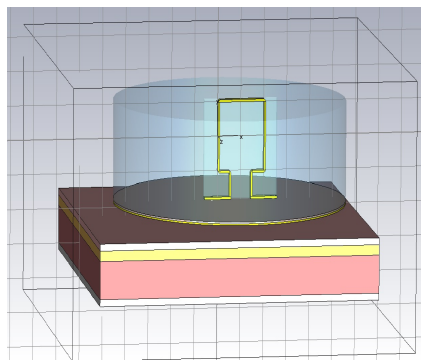

(b)

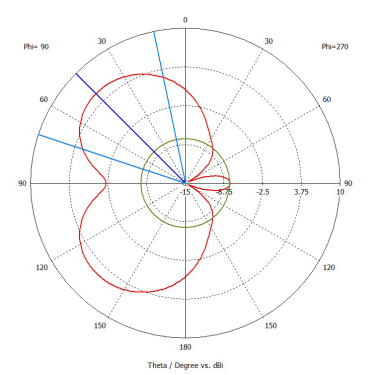

(d)
Fig.11. (a) A loop antenna with four layer phantom (skin, fat, muscle and bone). (b) A loop antenna with Rohacell on it. (c) $\left|\mathrm{S}_{11}\right|$ with and without Rohacell. (d) Far field radiation patterns of the loop antenna.

\section{REFERENCES}

[1] P. S. Hall, "Antennas and propagation for body centric communications," IET Semin. Antennas Propag. Body-Centric Wirel. Commun., pp. 1-4, 2007.

[2] N. Rais, P. Soh, and F. Malek, "A review of wearable antenna," Antennas Propag. Conf. LAPC 2009., no. November, pp. 225-228, 2009.

[3] a. a. Serra, P. Nepa, G. Manara, and P. S. Hall, "Diversity Measurements for On-Body Communication Systems," Antennas Wirel. Propag. Lett., vol. 6, no. 11, pp. 361-363, 2007.

[4] A. A. Serra, P. Nepa, G. Manara, and P. S. Hall, "Experimental investigation of diversity techniques for on-body communication systems," IET Semin. Antennas Propag. Body-Centric Wirel. Commun., pp. 63-66, 2007.

[5] P. Hall and Y. Hao, "Antennas and propagation for on-body communication systems," IEEE Antennas Propag. Mag., vol. 49, no. 3, pp. 41-58, 2007.

[6] A. Sani, S. Member, Y. Zhao, Y. Hao, and S. Member, "An Efficient FDTD Algorithm Based on the Equivalence Principle for Analyzing Onbody Antenna Performance," vol. 57, no. 4, pp. 10061014, 2009.

[7] I. Khan, P. S. Hall, A. A. Serra, A. R. Guraliuc, and P. Nepa, "Diversity Performance Analysis for On-Body Communication Channels at 2 . 45 GHz," vol. 57, no. 4, pp. 956-963, 2009.

[8] S. Bashir and A. Chauraya, "A flexible fabric metasurface for on body communication applications," ..., 2009. LAPC 2009. ..., no. November, pp. 725-728, 2009.

[9] A. Michalopoulou, A. A. Alexandridis, K. Peppas, T. Zervos, F. Lazarakis, K. Dangakis, and D. I. Kaklamani, "Statistical analysis for on-body spatial diversity communications at $2.45 \mathrm{GHz}$," IEEE Trans. Antennas Propag., vol. 60, no. 8, pp. 4014-4019, 2012.

[10] A. Michalopoulou, A. A. Alexandridis, K. Peppas, T. Zervos, F. Lazarakis, K. Dangakis, and D. I. Kaklamani, "On-body channel statistical analysis based on measurements in an indoor environment at 2.45 GHz," IET Microwaves, Antennas Propag., vol. 6, no. 6, p. 636, 2012.

[11] A. Michalopoulou, T. Zervos, K. Peppas, F. Lazarakis, A. a. Alexandridis, K. Dangakis, and D. I. Kaklamani, "The influence of the wearable antenna type on the on-body channel modeling at 2.45 GHz," Eur. Conf. Antennas Propag., pp. 3044-3047, 2013. 
[12] M. Gallo, P. S. Hall, M. Bozzettil, I. Bari, and V. Orabona, "Use of Animation software in the simulation of On-body Communication Channels," vol. 2, no. 6037, p. 705, Sep. 1976

[13] N. Chavannes and R. Tay, "Suitability of FDTD-based TCAD tools RF design of mobile phones," IEEE Antennas Propag. Mag., vol. 45 , no. $6,2003$.

[14] W. Scanlon, G. Crumley, and N. E. Evans, "Body-obstructed fading characteristics of an in-ward $2.45 \mathrm{GHz}$ biomedical telecommand link," Antennas Propag. Soc. Int. Symp., pp. 380-383, 1999.

[15] W. Whittow, C. J. Panagamuwa, R. M. Edwards, and J. C. Vardaxoglou, "Specific absorption rates in the human head due to circular metallic earrings at $1800 \mathrm{MHz}, "$ Loughbrgh. Antenna Propag. Conf., no. April, pp. 277-280, 2007.

[16] W. G. Whittow, C. J. Panagamuwa, R. M. Edwards, and J. C. Vardaxoglou, "On the effects of straight metallic jewellery on the specific absorption rates resulting from face-illuminating radio communication devices at popular cellular frequencies.," Phys. Med. Biol., vol. 53, no. 5, pp. 1167-82, Mar. 2008.

[17] M. Khattak, R. Edwards, and O. Ojerinde, "A study of perturbations in linear and circular polarized antennas in close proximity to the human body and dielectric liquid filled rectangular and a cylindrical phantom," in Loughborough Antenna \& Propagation Conference, 2010, no. November, pp. 409-412.

[18] SPEAG, OTA Phantoms User Manual. 2011.

[19] W. G. Scanlon, G. A. Conway, and S. L. Cotton, "Antennas and propagation considerations for robust wireless communications in medical body area networks," IET Semin. Antennas Propag. BodyCentric Wirel. Commun., pp. 37-37, 2007.

[20] M. R. Kamarudin, Y. I. Nechayev, and P. S. Hall, "Performance of Antennas in the On-Body Environment," 2005 IEEE Antennas Propag. Soc. Int. Symp., vol. 3A, pp. 475-478, 2005.
[21] W. G. Scanlon and S. L. Cotton, "Understanding On-Body Fading Channels at $2.45 \mathrm{GHz}$ using measurement based on user state and environment," in Loughborough Antenna \& Propagation Conference, 2008, no. March, pp. 10-13.

[22] S. Cotton and W. Scanlon, "Characterization of the on-body channel in an outdoor environment at $2.45 \mathrm{GHz}, " 2009$ 3rd Eur. Conf. Antennas Propag., pp. 722-725, 2009.

[23] S. Cotton and W. Scanlon, "A Statistical Analysis of Indoor Multipath Fading for a Narrowband Wireless Body Area Network," 2006 IEEE 17th Int. Symp. Pers. Indoor Mob. Radio Commun., pp. 1-5, Sep. 2006.

[24] P. Hall, Y. Hao, and S. Cotton, "Progress in antennas and propagation for body area networks," Signals Syst. Electron. ISSSE 2010 Int. Symp., vol. 1, 2010.

[25] G. A. Conway, W. G. Scanlon, and S. L. Cotton, "The performance of on-body wearable antennas in a repeatable multipath environment," 2008 IEEE Antennas Propag. Soc. Int. Symp., pp. 14, Jul. 2008.

[26] S. Park and S. Jayaraman, "Enhancing the quality of life through wearable technology," Eng. Med. Biol. Mag., no. June, pp. 41-48, 2003

[27] W. Scanlon, "Antenna-body interaction effects in a $418 \mathrm{MHz}$ radio telemeter for infant use," Eng. Med. Biol. Soc., pp. 278-279, 1996.

[28] R. Edwards and M. Khattak, "Understanding Body-centric antennas," Antennas Propag. Conf. LAPC 2010 Loughbrgh., no. November, pp. 629-632, 2010.

[29] A. Lea, P. Hui, J. Ollikainen, and R. G. Vaughan, "Propagation between on-body antennas," IEEE Trans. Antennas Propag., vol. 57, no. 11, pp. 3619-3627, 2009.

[30] Nordic Semiconductor, " $\lambda / 4$ printed monopole antenna for $2.45 \mathrm{GHz}$," no. January, pp. 2-7, 2005

[31] "http://www.empire.de/.". 